\title{
Experimental research and ANN modeling on the impact of the ball burnishing process on the mechanical properties of 5083 Al-Mg material
}

\author{
H. Basak ${ }^{1 *}$, M. T. Ozkan ${ }^{1}$, I. Toktas ${ }^{2}$ \\ ${ }^{1}$ Gazi University Faculty of Technology, Industrial Design Engineering Department, Ankara, Turkey \\ ${ }^{2}$ Yıldırım Beyazıt University, Faculty of Engineering and Natural Sciences, Mechanical Engineering Department, \\ Ankara, Turkey
}

Received 26 April 2016, received in revised form 17 December 2018, accepted 18 December 2018

\begin{abstract}
$5083 \mathrm{Al}-\mathrm{Mg}$ is the widely used material in food, chemistry, vehicle, machinery, and construction sectors, as well as in the aviation and space industries. The burnishing is normally used as the finishing operation for this material with the advantages such as surface roughness, reduced fracture formation, hardness, fatigue strength, and an increase of the wear resistance. These positive improvements are dependent on burnishing process parameters such as feed rate, burnishing force, ball diameter, and a number of revolutions. The study contains determination and optimization of the machining parameters and their effects on the surface roughness, microhardness, and the strength of $5083 \mathrm{Al}-\mathrm{Mg}$ material in the ball burnishing processes. Multiple regression and ANOVA analysis were performed to identify significant process parameters. A new Artificial Neural Networks (ANN) model with different neuron structures and algorithms has also been developed using experimental results to supplement the multiple regression model as the desired $R^{2}$ values could not be achieved with the latter. The ANOVA analysis indicated that both the burnishing force and the number of revolutions have a significant effect on the surface roughness and hardness with optimums $300 \mathrm{~N}$ and 200 rpm, respectively. Results from the two models were compared with each other. The developed ANN model is shown to estimate the surface roughness and the surface hardness with high reliability $\left(R^{2}=0.999992\right)$ without costly experimental trials.
\end{abstract}

Ke y w or d s: burnishing, surface roughness and hardness, microhardness, strength analysis, Artificial Neural Networks (ANN)

\section{Introduction}

The burnishing process is defined as the cold finishing process without machining the surface of the workpiece. There are many factors affecting the surface roughness and surface hardness during the ball burnishing process. Some of these factors could be mentioned as the physical and mechanical properties of the workpiece, the chemical composite, the tool material and tool geometry, the surface quality and rigidity, the kinematics of the cooling and lubrication equipment, the heat transfer property and liquidity, and the characteristics of the processing or shaping process $[1-4]$. The purpose of the burnishing process can be explained as the improvement of the surface roughness [5-10], wear, corrosion [11-13], fatigue resistance and tensile strength $[11,12,14]$, and the microhardness [15-17] values of the workpiece as well as attaining dimensional precision. This processing method is preferred because of its high productivity in mass production compared to the grinding process.

The burnishing process is applied using different materials such as aluminum and its alloys (cast Al$\mathrm{Cu}$ alloy, 7075 T6, AA2014, AA 7178, AA 7075, 6061-T6, Al 6061) [1, 11, 15, 17, 18-26] and steel (plastic formwork steels, steel, heat-processed and tempered steel, hardened steel, AISI 5140, St37, X5CrNiMo17-12-2) [6, 27-38], polymers [39], brass [25, 40], tita-

*Corresponding author: e-mail address: hbasak@gmail.com 
Table 1. Mechanical properties of the $5083 \mathrm{Al}-\mathrm{Mg}$ material

\begin{tabular}{cccccccccccc}
\hline $\mathrm{Si}$ & $\mathrm{Fe}$ & $\mathrm{Cu}$ & $\mathrm{Mn}$ & $\mathrm{Mg}$ & $\mathrm{Cr}$ & $\mathrm{Zn}$ & $\mathrm{Ti}$ & \multicolumn{2}{c}{ Others } \\
\hline 0.40 & 0.40 & 0.10 & $0.40-1.00$ & $4.00-4.90$ & $0.05-0.25$ & 0.25 & 0.15 & 0.05 & 0.15 \\
\hline
\end{tabular}

Table 2. Experimental parameters for $5083 \mathrm{Al}-\mathrm{Mg}$ material to be burnished

\begin{tabular}{cccc}
\hline Burnishing force $(\mathrm{N})$ & Feed rate $\left(\mathrm{mm} \mathrm{rev}^{-1}\right)$ & Number of revolutions (rpm) & Ball diameter (mm) \\
\hline $100-200-300-400$ & $0.15-0.25-0.35-0.45$ & $100-200-300$ & $11.112-13.494-15.08-16.669$ \\
\hline
\end{tabular}

nium [35], and copper [25]. An increase in the burnishing force has a positive impact on the surface roughness and hardness, and distortions may occur on the surface after specific values of the force. Also, low feed rate values yield better surface roughness and hardness. Furthermore, an increase of the ball diameter has a positive effect on the surface roughness and microhardness. Improved surface roughness values are obtained with the increase in the ball diameter when compared to smaller ball diameters. The increase of the ball diameter also increases the surface hardness value. As generally expressed in the literature, the surface roughness increases together with the increase in the number of revolutions (rpm). After a certain number of revolutions, degradation may also occur on the material leading to surface deterioration.

The purpose of this study is an experimental examination of the impacts of the feed rate, burnishing force, ball diameter, and number of revolution parameters on the surface roughness, microhardness, and strength in the burnishing process for the 5083 $\mathrm{Al}-\mathrm{Mg}$ material. The attained results were assessed with multiple regression analysis, and because the desired $R^{2}$ value could not be found, an ANN (Artificial Neural Networks) model was developed. Also, it was determined which ones of the experimental parameters have the main impact on the surface roughness and hardness by conducting ANOVA analysis. Finally, the ANN model was attained by using different neuron structures, and algorithms and the accomplished experiment result data were then compared.

\section{Material and method}

The samples of the $5083 \mathrm{Al}-\mathrm{Mg}$ material used in the experiments were prepared in dimensions of $150 \times 100 \times 10 \mathrm{~mm}^{3}$. The mechanical properties of the material are given in Table 1.

An apparatus which could burnish the prismatic parts and could be used in the vertical processing centered milling machine, the tip of which was formed as ball geometry was used as a crushing tool (Figs. 1a-c).

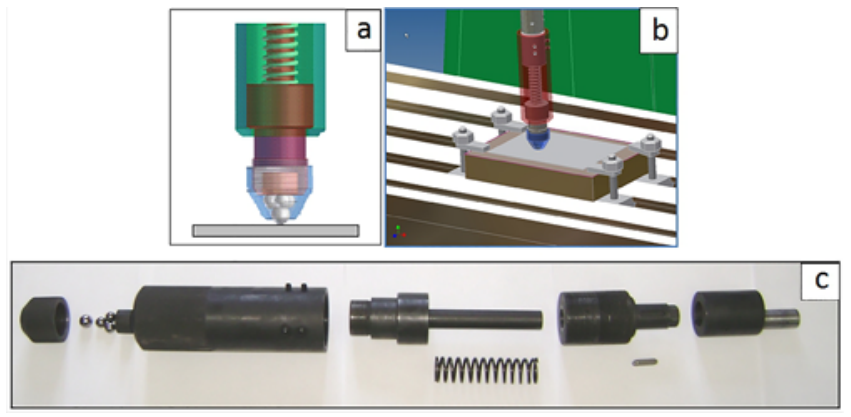

Fig. 1. Burnishing apparatus (1).

The spring system was used to adjust the burnishing force during the burnishing and reducing the vibration that would occur due to the eccentric movement in the work mill of the bench to a minimum level.

A fixture was designed and manufactured to fix and unfix the experimental samples to the bench table permanently in the same way and connect it rigidly. In the experiments, a Taksan 40T1500 vertical processing centered CNC milling machine and cooling liquid were used. Other variable parameters used in the experiment are given in Table 2 .

A measurement with four repetitions was carried out for the surface roughness and hardness out of each experimental sample. The averages of the measured values were taken, and the average surface roughness and hardness values were attained depending on the processing conditions. The average surface roughness belonging to the aluminum parts that were not subjected to the burnishing process were measured as $5.26 \mu \mathrm{m}$, and the average surface hardness was measured as 14.6 HB. Mitutoyo Surftest Sj-201 test tool was used to measure the surface roughness in the experiments, and the Digirock-Rbov test tool was used to measure the surface hardness.

\section{Surface roughness and surface hardness}

The impacts of the parameters such as variable 
feed rate, burnishing force, ball diameter, and a number of revolutions used during the burnishing process on the surface roughness and hardness were examined.

\subsection{The impact of the burnishing force on the surface roughness and hardness}

By considering all the variables, when the graphics given in Fig. 2a are examined, it can be observed that the increase of the burnishing force and the number of revolutions generally has a degradation effect on the surface roughness. As the compressive force increases, the surface roughness value increases. At the same time, it could also be seen from the figure that the increase in the number of revolutions causes the formation of distortions on the surface.

The minimum surface roughness value $\left(\mathrm{SR}_{\mathrm{MIN}}\right)$, maximum surface roughness value $\left(\mathrm{SR}_{\mathrm{MAx}}\right)$, average surface roughness values $\left(\mathrm{SR}_{\mathrm{AVE}}\right)$ and total surface roughness variation (TSRV) attained in the regional transitions are given in the graphics. The best surface roughness value was measured as $\mathrm{SR}_{\mathrm{AVE}}=0.45 \mu \mathrm{m}$ on average under $100 \mathrm{~N}$ burnishing force and $100 \mathrm{rpm}$. As the number of revolutions increases especially with the burnishing force of 100,200 , and $300 \mathrm{~N}$ the surface roughness increases. The $400 \mathrm{~N}$ burnishing force maximizes the surface roughness at the highest number of revolutions (i.e., $300 \mathrm{rpm}$ ), Fig. 2a.

When the graphics given in Fig. $2 \mathrm{~b}$ were examined, in general, it is observed that depending on the number of revolutions, the burnishing force has a positive impact on the surface hardness; as the burnishing force increases, the surface hardness value also increases. At the same time, it can also be said that the increase in the number of revolutions causes no significant increase in hardness.

The minimum surface hardness value $\left(\mathrm{SH}_{\mathrm{MIN}}\right)$, maximum surface hardness value $\left(\mathrm{SH}_{\mathrm{MAX}}\right)$, average surface hardness values $\left(\mathrm{SH}_{\mathrm{AVE}}\right)$ and the total surface hardness variation (TSHV) attained in the regional transitions are given in the graphics. The best surface hardness value was measured as $\mathrm{SH}_{\mathrm{AVE}}=34.25 \mathrm{HB}$ on average under $400 \mathrm{~N}$ burnishing force and $300 \mathrm{rpm}$.

\subsection{The impact of the feed rate on the surface roughness and hardness}

When the graphics given in Fig. 3a are examined, it can be observed that depending on the number of revolutions, the increase in the feed rate has a negative impact on the surface roughness. As the feed rate value increases, the surface roughness value deteriorates. On the other hand, an increase in the number of revolutions causes improvements on the surface roughness. $\mathrm{SR}_{\mathrm{MIN}}, \mathrm{SR}_{\mathrm{MAX}}, \mathrm{SR}_{\mathrm{AVE}}$, and TSRV in the regional transitions are given in Fig. 3a. The best surface roughness value was measured on average as $\mathrm{SR}_{\mathrm{AVE}}=$
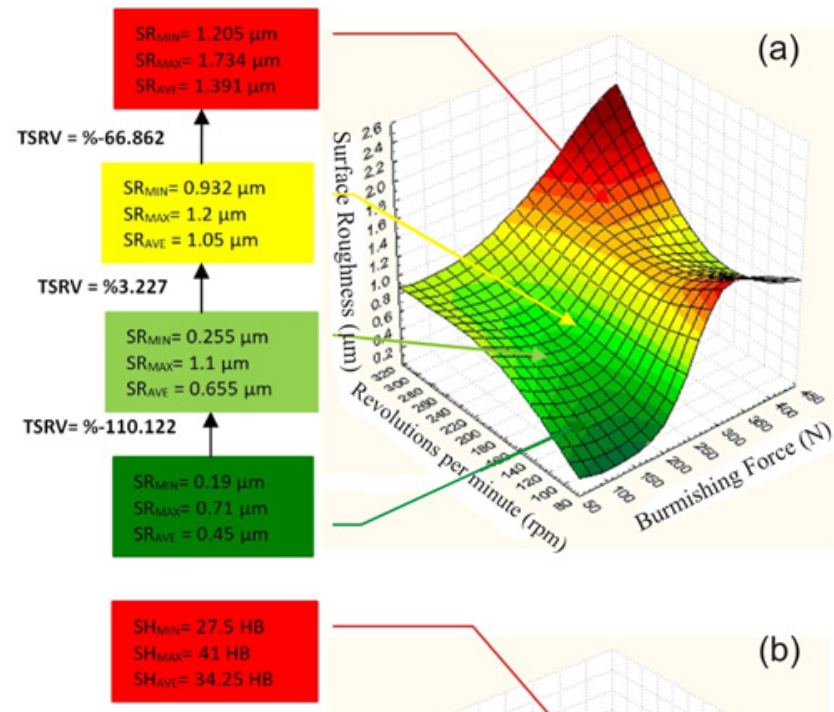

(b)

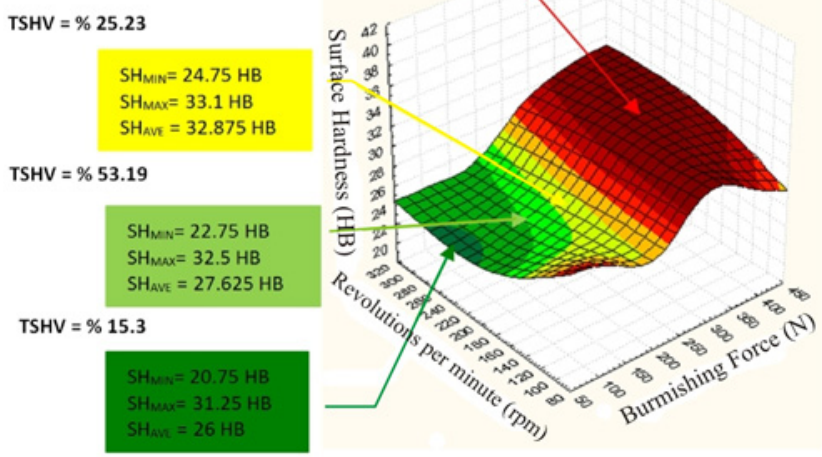

Fig. 2. Effects of the revolutions per minute and burnishing force on surface roughness (a) and surface hardness (b).

$0.37 \mu \mathrm{m}$ in $0.15 \mathrm{~mm} \mathrm{rev}^{-1}$ feed rate and $300 \mathrm{rpm}$. Generally, lower feed rates (i.e., 0.15 and $0.25 \mathrm{~mm} \mathrm{rev}^{-1}$ ) yield better surface roughness values as compared to higher feed rates (i.e., 0.35 and $0.45 \mathrm{~mm} \mathrm{rev}^{-1}$ ) especially at 100 and $200 \mathrm{rpm}$.

When the graphics in Fig. 3b are examined, in general, the surface hardness changes in direct proportion to the feed rate and changes in inverse proportion with the number of revolutions. The best hardness value was attained in the parameters in which the feed rate is at a maximum level, and a number of revolutions is at a minimum level. $\mathrm{SH}_{\mathrm{MIN}}$, $\mathrm{SH}_{\mathrm{MAX}}, \mathrm{SH}_{\mathrm{AVE}}$, and total surface hardness variation TSHV values attained in the regional transitions are given in the graphics. The best surface hardness value was measured on average as $\mathrm{SH}_{\mathrm{AVE}}=34.25 \mathrm{HB}$ at $0.45 \mathrm{~mm} \mathrm{rev}^{-1}, 100 \mathrm{rpm}$. Regional improvement $(\sim 33 \mathrm{HB})$ was observed in the surface hardness at $0.15 \mathrm{~mm} \mathrm{rev}^{-1}$ and $300 \mathrm{rpm}$.

\subsection{The impact of the ball diameter on the surface roughness and hardness}

When the graphics given in Fig. 4a are examined, 

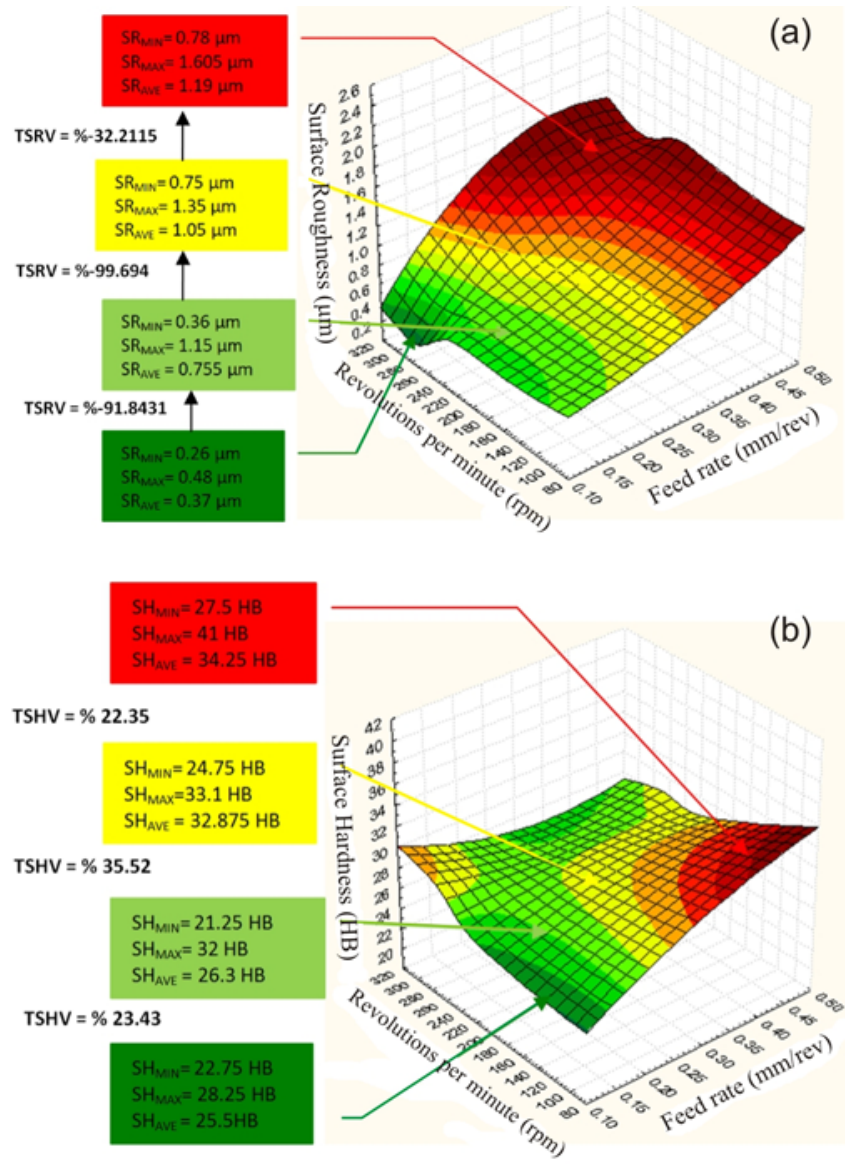

Fig. 3. Effects of the revolutions per minute and feed rate on surface roughness (a) and surface hardness (b).

it is observed that depending on the number of revolutions, the increase in the ball diameter ( $\mathrm{mm}$ ) of the burnishing apparatus has a positive impact on the surface roughness. As the ball diameter increases, the surface roughness value was improved. According to Fig. 4a, it can be said that the increase in the number of revolutions causes distortions on the surface. $\mathrm{SR}_{\mathrm{MIN}}, \mathrm{SR}_{\mathrm{MAX}}, \mathrm{SR}_{\mathrm{AVE}}$, and TSRV in the regional transitions are given in Fig. 4a. The best surface roughness value was measured as an average $\mathrm{SR}_{\mathrm{AVE}}=$ $0.58 \mu \mathrm{m}$ at $16.669 \mathrm{~mm}$ ball diameter, $300 \mathrm{rpm}$.

When the graphics in Fig. 4b are examined, in general, the surface hardness changes in direct proportion to the ball diameter and number of revolutions. The best hardness value was attained in the parameters in which the ball diameter is at the maximum level, and a number of revolutions is at the minimum level. $\mathrm{SH}_{\mathrm{MIN}}, \mathrm{SH}_{\mathrm{MAX}}, \mathrm{SH}_{\mathrm{AVE}}$, and total surface hardness variation TSHV values attained in the regional transitions are given in the graphics. The best surface hardness value was measured as average $\mathrm{SR}_{\mathrm{AVE}}=28.5 \mathrm{HB}$ at $16.669 \mathrm{~mm}$ ball diameter and $100 \mathrm{rpm}$.
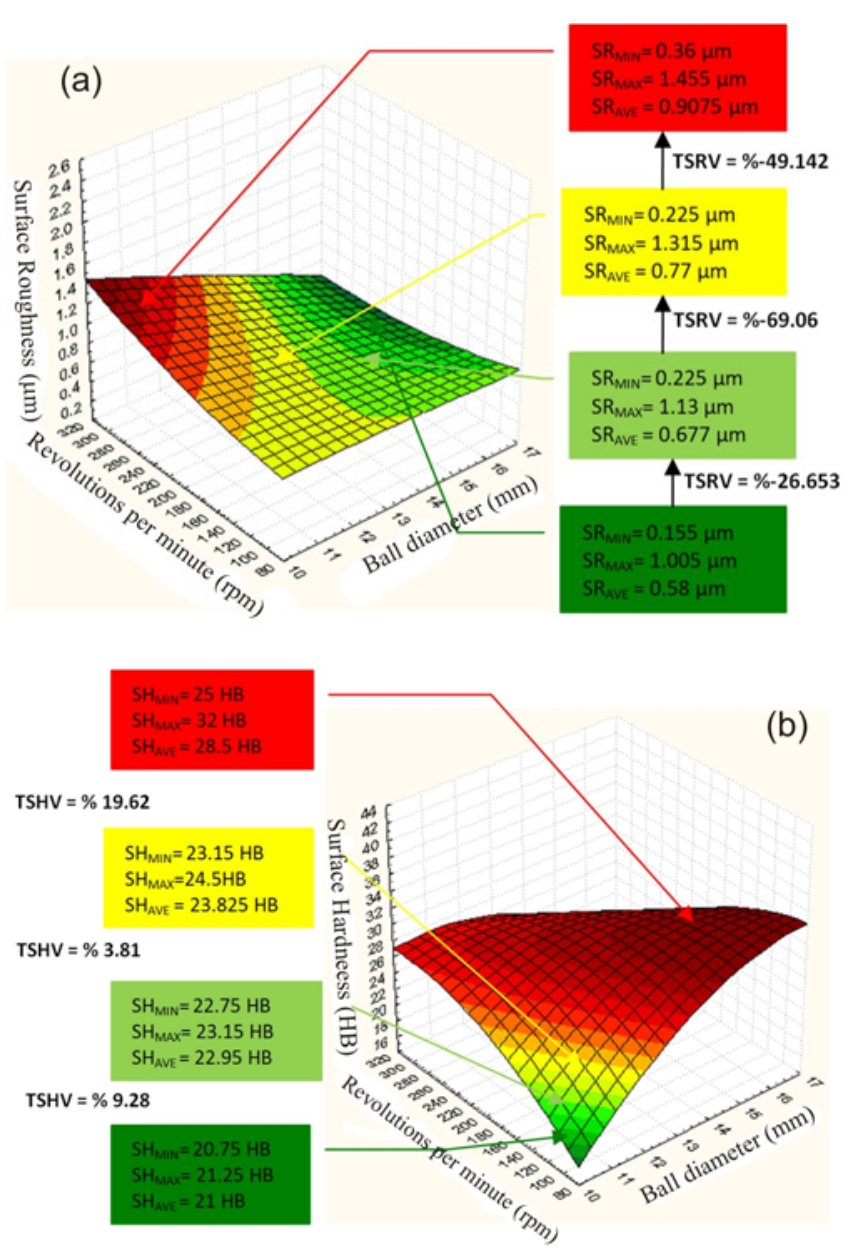

Fig. 4. Effects of the revolutions per minute and ball diameter on surface roughness (a) and surface hardness (b).

\section{Tensile tests}

For the tensile test, firstly, the tension samples following the standards were prepared out of the 5083 Al-Mg material tested. The ELISTA universal broaching machine was used for this process. Some samples which were subjected to the tension process are given in Fig. 5b as an example. A measurement with three repetitions was carried out for the tension experiment out of each experimental sample, and the average of the measured values was taken.

The increase in the feed rate negatively affects the strength when the same parameters are used. The strength of the workpiece is adversely affected by increasing feed which causes reduced crushing on the surface of the workpiece. Examining the correlation between the compressive force and the strength, on the other hand, an increase in the former contributes positively to the latter values (Fig. 6a).

The increase in the ball diameter positively affects the strength. When this result is examined, it can be said that the sinking rate of the ball is more in the 


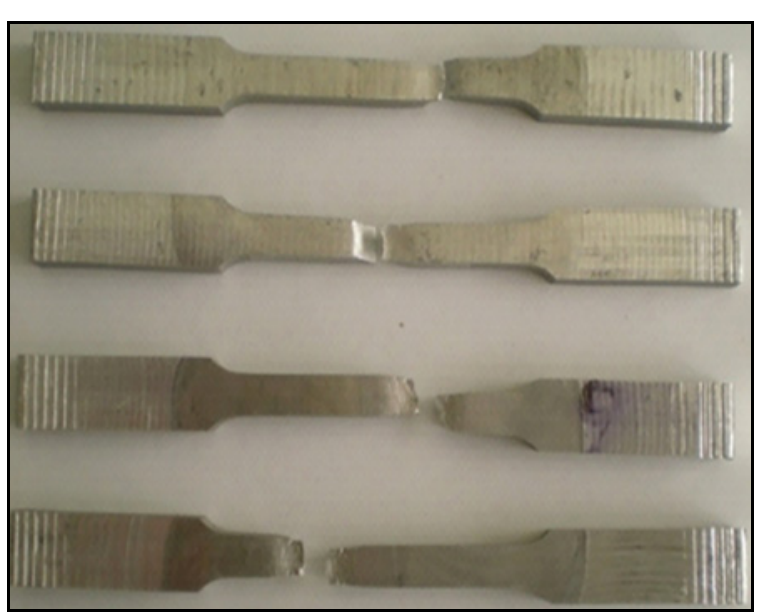

Fig. 5. Example samples having been subjected to the tensile process.

ball with a small diameter under the same parameters, and this reflects on the surface roughness negatively. The surface roughness occurs on the surface of the part as grooves and ridges which are not visible to the naked eye. The more the surface of the part is crashed, the less these grooves and ridges shall occur. This is achieved with the diameter of the ball having the largest surface area. This situation was reflected on the attained graphics, and better tensile strength results were attained in the burnished parts whose ball diameter is greater when compared to the others. The tensile strength increases as the number of revolutions increases. The component strength increases with increasing number of revolutions which enhances the extent of crashing on the workpiece surface (Fig. 6b).

\section{Microhardness}

The prismatic parts taken from the samples were used to be able to detect how much and at what ratios the part that was subjected to the burnishing process had increased the hardness towards the inside from the surface.

The microhardness measurements were carried out in $0.5 \mathrm{~mm}$ increments starting from $0.1 \mathrm{~mm}$ below the burnished surface (Fig. 7). The effects of the experimental parameters (feed rate, number of revolutions, ball diameter and burnishing force) used in burnishing
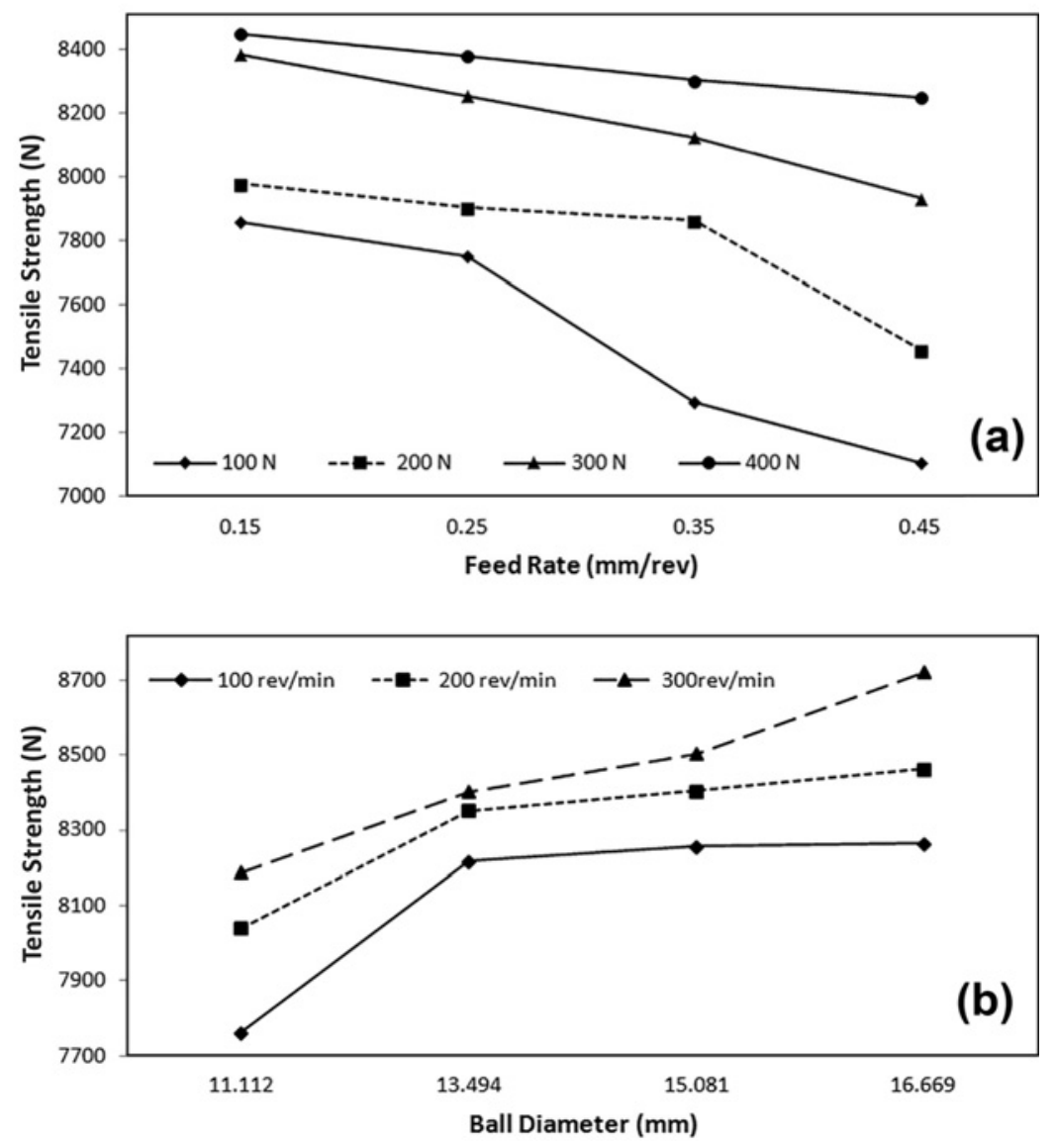

Fig. 6. The impact of the parameters having been used in the experiments on the tensile strength: (a) effects of burnishing force and feed rate on tensile strength and (b) effects of ball diameter and a number of revolutions on tensile strength. 


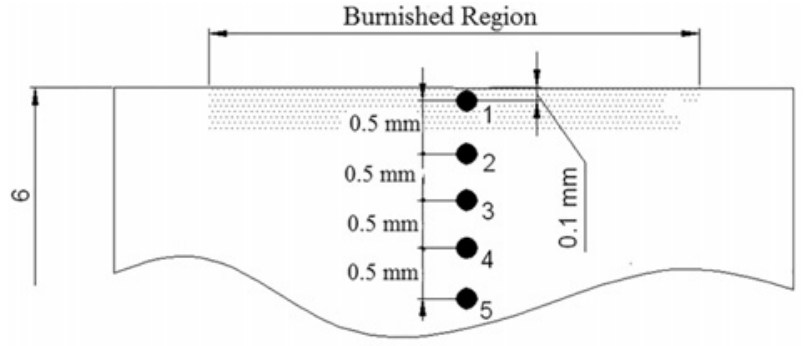

Fig. 7. Taking the experimental sample part for the microhardness measurement.

operation on microhardness were investigated.

The SHIMADZU branded microhardness tester was used for the measurement of the microhardness. Examining the microhardness results in Fig. 8, it can generally be observed that the microhardness values of the aluminum part decreased towards the part depth, considering that the average surface microhardness before burnishing was $90 \mathrm{HV}$ (Fig. 8).

When Fig. 8a is examined, it can be seen that the increase in the burnishing force positively affects the microhardness. It is already expected that the burnishing process on the part surface reduces the microhardness from certain depth onwards. Nevertheless, even in the test sample with a minimum burnishing force $(100 \mathrm{~N})$, the microhardness result was better than the raw material at all measured depths.

It is observed that the microhardness is negatively affected as the feed rate increases (Fig. 8b). As the feed rate decreases, burnishing time on the surface of the workpiece increases, and consequently, the resulting microhardness in the workpiece is more pronounced. As can be understood from the fact that the last measured value was $92 \mathrm{HV}$ in Fig. $8 \mathrm{~b}$, it can be said that the burnishing process affected the microhardness towards the inside of the part up to $2-2.5 \mathrm{~mm}$. It has been seen that the increase in the ball diameter negatively affects the microhardness. If the microhardness and the impact on the inside of the part were requested as high, it was revealed that the ball diameter should be kept small. This can be explained by the fact that the balls with smaller diameter better penetrate the part, thus affecting microhardness positively.

It is also seen in the attained results that the increase in the number of revolutions is positively reflected on the microhardness (Fig. 8c,d).

\section{Artificial Neural Network (ANN) model}

A neuron is the basic element of neural networks, and depending on its duties its shape and size may vary. Analyzing a neuron regarding its activities is important, since understanding the way it works also helps us to construct the ANNs. An ANN may be seen as a black box which contains hierarchical sets of neurons (e.g., processing elements) producing outputs for certain inputs [42-46].

Each processing element consists of data collection, processing the data and sending the results to the relevant consequent element. The whole process may be viewed regarding the inputs, weights, the summation function, and the activation function (Fig. 9).

According to Fig. 9, we have the following:

- The inputs are the activity of collecting data from the relevant sources.

- The weights control the effects of the inputs on the neuron. In other words, an ANN saves its information over its links, and each link has a weight. These weights are constantly varied while trying to optimize the relationship between the inputs and outputs.

- Summation function is to calculate the net input readings from the processing elements.

- Transfer (activation) function determines the output of the neuron by accepting the net input provided by the summation function. There are several transfer functions like summation function. Depending on the nature of the problem, the determination of transfer and summation function is made. A transfer function generally consists of algebraic equations of linear or nonlinear form. The use of a nonlinear transfer function makes a network capable of storing nonlinear relationships between the input and the output. A commonly used function is a sigmoid function because it is self-limiting and has a simple derivative. An advantage of this function is that the output cannot grow infinitely large or small.

- Outputs accept the results of the transfer function and present them either to the relevant processing element or to the outside of the network.

The functioning of ANNs depends on their physical structure. An ANN may be regarded as a directed graph containing a summation function, a transfer function, its structure, and the learning rule used in it. The processing elements have links in between them forming a layer of networks. A neural network usually consists of an input layer, some hidden layers, and an output layer [42-46].

Firstly, multiple regression analysis was performed. According to analysis, $R^{2}=0.52356451$ and adjusted $R^{2}=0.48891465$ values were calculated using Statistica software. These $R^{2}$ values have not any meaning statistically. Secondly, ANOVA analysis was also performed. It has been observed that respectively the burnishing force, feed rate, ball diameter, and a number of revolutions have an impact on the surface roughness and hardness. Both multiple regression analysis and ANOVA analysis results did not acquire more progress for predicting surface roughness and surface hardness. Because of this, an ANN model was developed.

In this study, the training and test data were prepared using experimental patterns. Data were ob- 

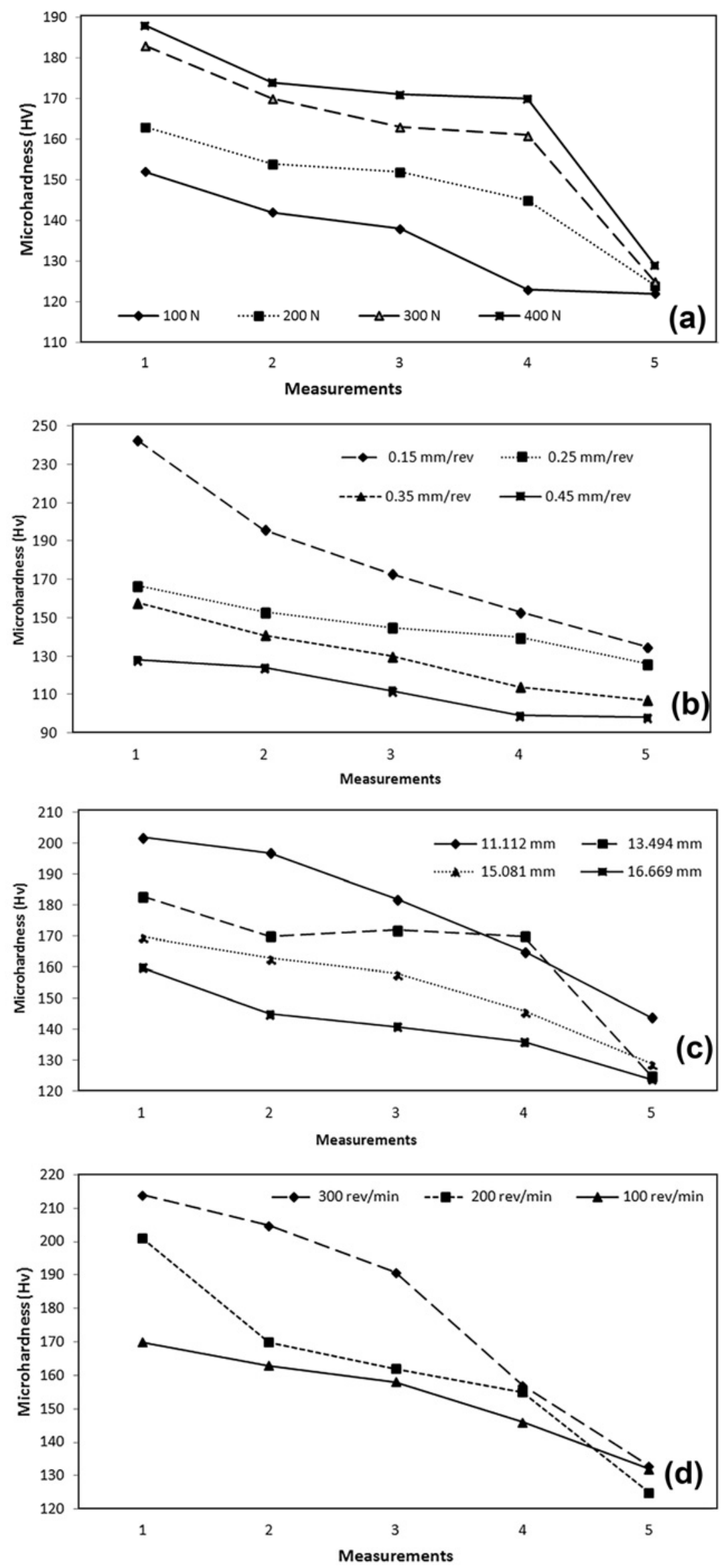

Fig. 8. The impact of the experimental parameters on the microhardness. 


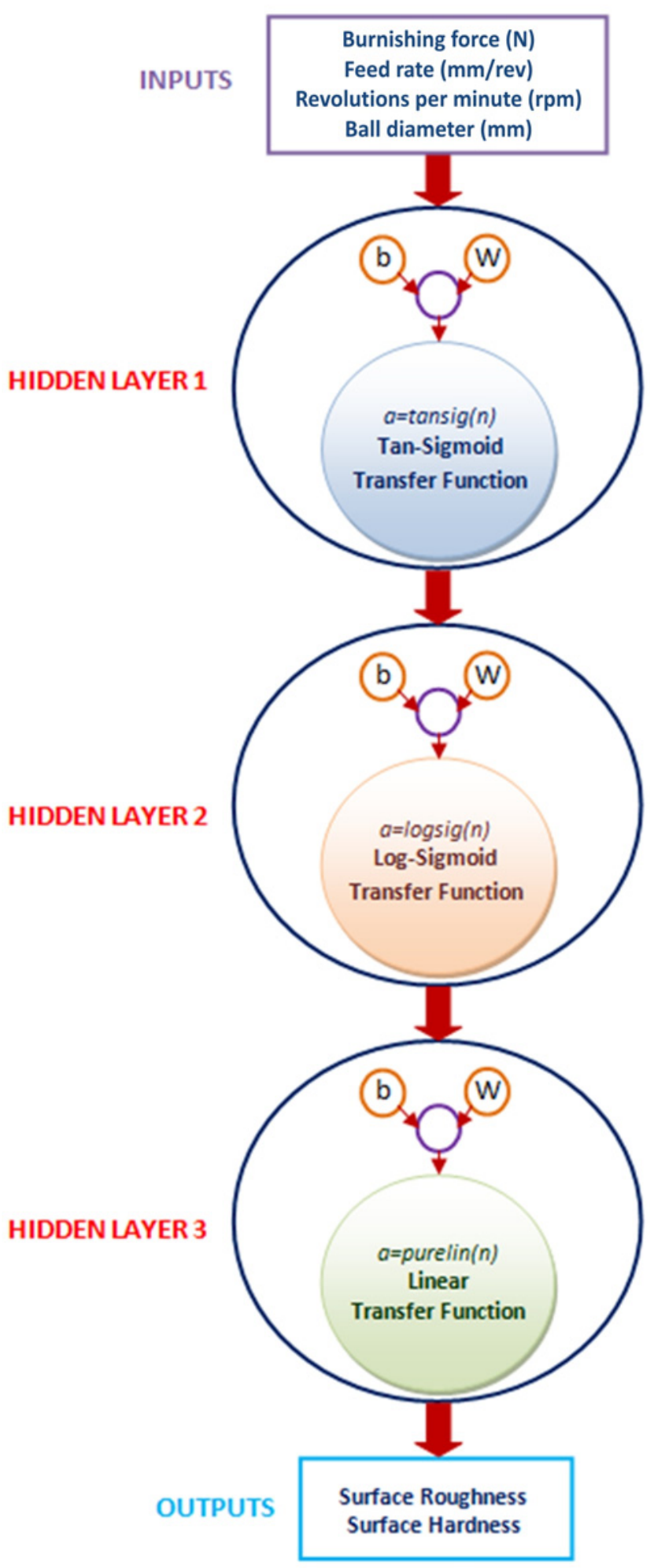

Fig. 9. Basic ANN model.

tained according to study parameters that had 60 rows $\times 6$ columns. About $30 \%$ data were used as test data, $70 \%$ data were used as training data. Burnishing force $(\mathrm{N})$, feed rate $\left(\mathrm{mm} \mathrm{min}^{-1}\right)$, number of rev- olutions (rpm), and ball diameter $(\mathrm{mm})$ were used as input layer, LM algorithm and MLP (Multi-Layer Perception) were used in the ANN model, surface roughness $(\mu \mathrm{m})$ and surface hardness (HB) were used as output layer of the ANNs. In the ANN model, tansig, logsig, and purelin transfer functions $(f)$ were used and expressed as follows (Eqs. (1)-(4)):

$$
\begin{gathered}
N E T_{\mathrm{i}}=\sum w_{i j} x_{j}+w_{\mathrm{bi}}, \\
a=\tan \operatorname{sig}(n)=\frac{1}{\left(1+\mathrm{e}^{-2 n}\right)}-1, \\
a=\log \operatorname{sig}(n)=\frac{1}{\left(1+\mathrm{e}^{-n}\right)}, \\
a=\operatorname{purelin}(n),
\end{gathered}
$$

where $N E T$ is the weighted sum of the input. Input and output values were normalized between 0 and 1 . In our case, a supervised learning approach was used in the model. Since the number of neurons found in the input and output layers is known, the best performance of the network with the number of hidden layers is determined using the trial-error method. Usually, an algorithm is used for the learning process; this algorithm determines the weights. There are various learning methods using these strategies - RBF, SCG, RBFT, etc. (Table 4). The back propagation learning algorithm has been used with Multi-Layer Perception (MLP) and Levenberg-Marquardt (LM) learning algorithm versions at the training and testing stages of the networks. The computer program has been developed under MATLAB.

In the first step of the training, a determination of the learning algorithms was made. The number of hidden layers and the number of neurons for each hidden layer were determined. Then, the number of iterations was entered by the user, and the training started. The training continues either to the end of the iterations or reaching the target level of errors. Figures 10 and 11 illustrate the ANN predictions against the empirical results. Figures 12 and 13 illustrate the best performance of ANN and regression results of the training.

\subsection{Testing the accuracy of Regression Analysis (REGA) and ANN-based analysis}

To understand whether a multiple REGA or an ANN is making good predictions, the test data was checked with unused data. The statistical methods of $R M S E, R^{2}$, and $M E P$ values were used for making comparisons. Same data obtained from REGA are used to determine the mentioned values. 


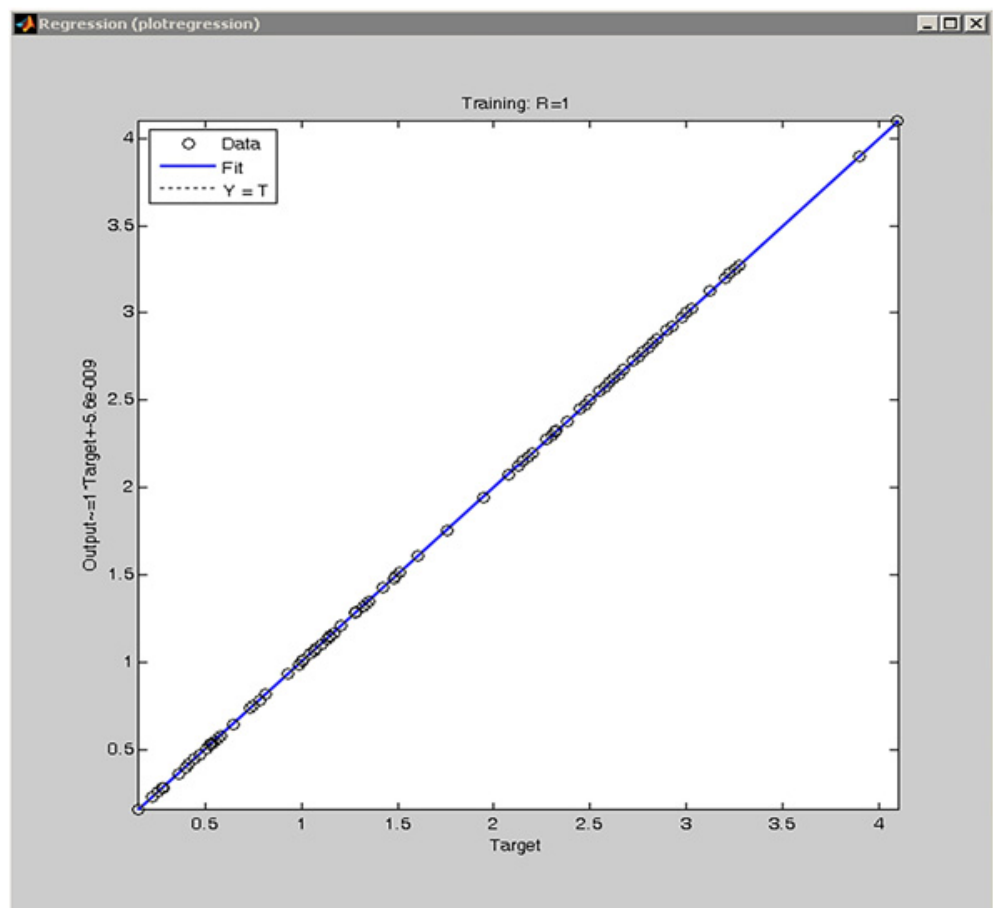

Fig. 10. The ANN predictions against the empirical-based results.

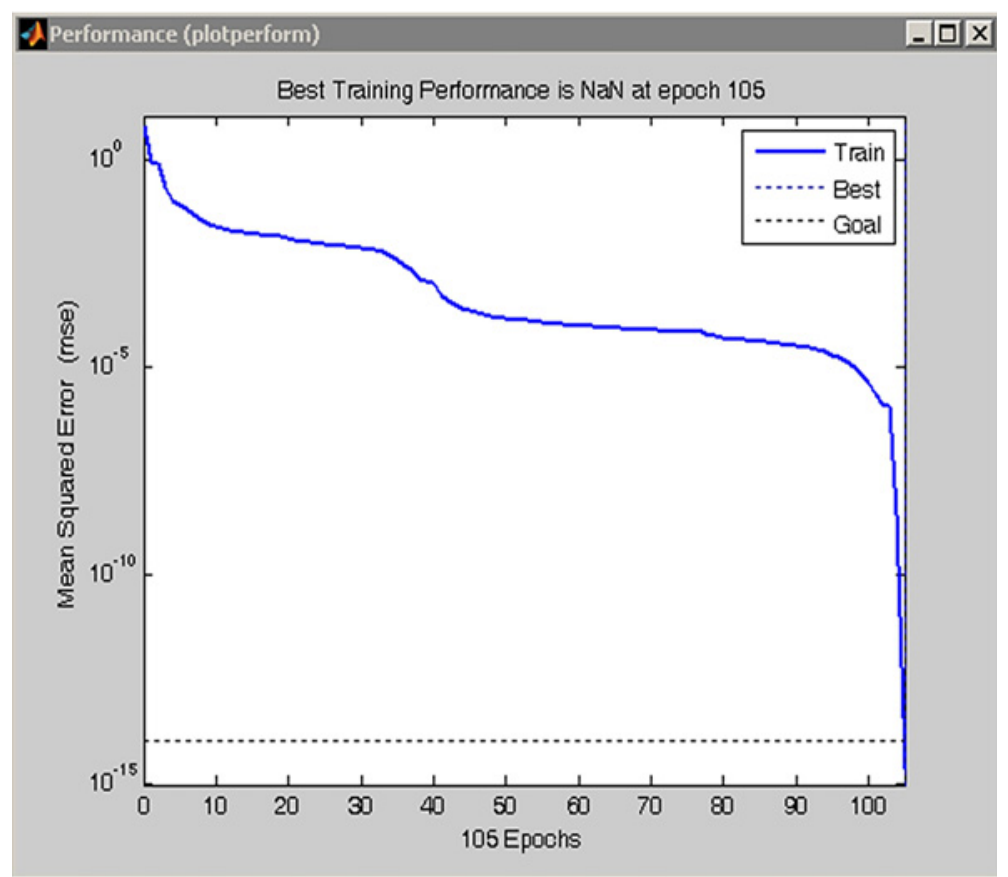

Fig. 11. The ANN predictions against the empirical-based results.

These values are determined by the following Eqs. $(5)-(7)$ :

$$
R M S E=\left((1 / p) \sum_{j}\left|t_{j}-o_{j}\right|^{2}\right)^{1 / 2}
$$

$$
R^{2}=1-\left(\frac{\sum_{j}\left(t_{j}-o_{j}\right)^{2}}{\sum_{j}\left(o_{j}\right)^{2}}\right),
$$




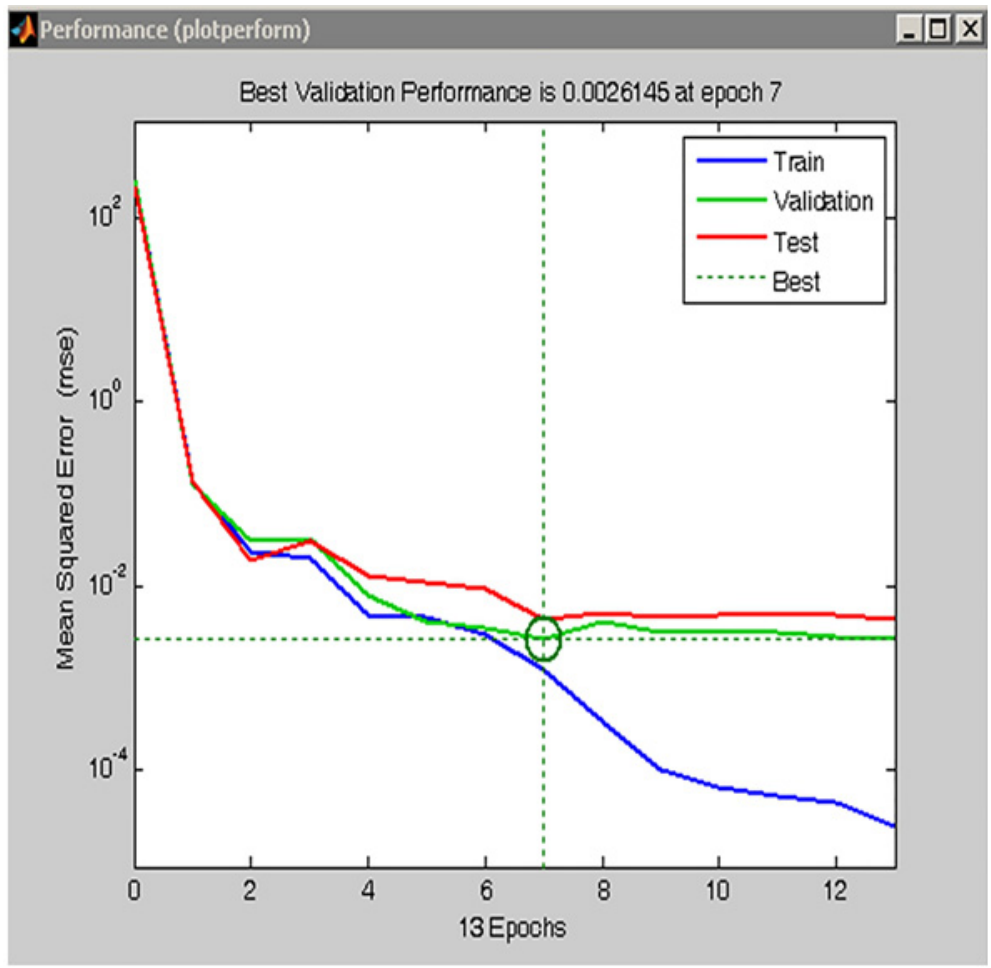

Fig. 12. Best performance of the ANN model.

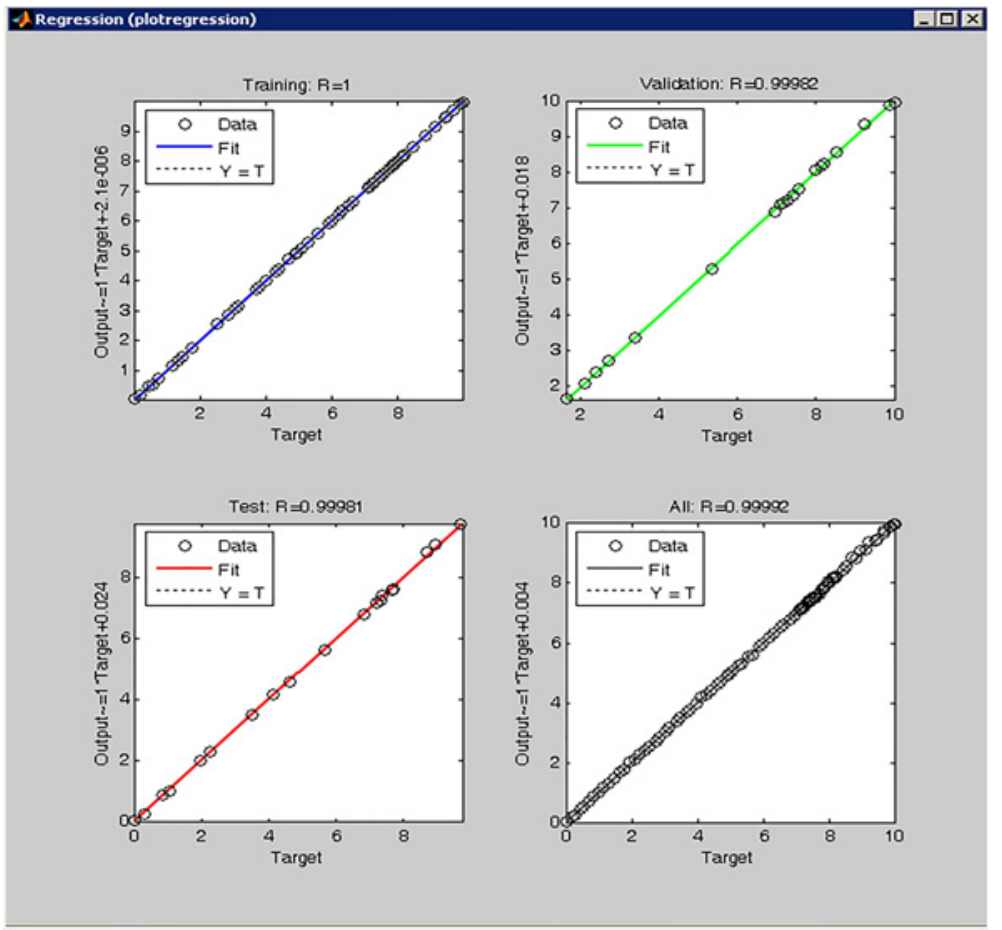

Fig. 13. Regression results of the ANN model.

$M E P=\frac{\sum_{j}\left(\frac{t_{j}-o_{j}}{t_{j}} \times 100\right)}{p}$ where $t$ is the target value, $o$ the output, and $p$ the number of samples.

Using the trial-error method, the structure of the network (i.e., the number of neurons and hidden layers) was changed, and the training operation was re- 
Table 3. Statistical errors for the outputs using various algorithms

\begin{tabular}{|c|c|c|c|c|c|c|c|c|}
\hline & $\begin{array}{c}\text { Net name } \\
\text { (hidden layers) }\end{array}$ & $\begin{array}{c}\text { Training } \\
\text { performance }\end{array}$ & $\begin{array}{c}\text { Test } \\
\text { performance }\end{array}$ & $\begin{array}{c}\text { Training } \\
\text { error }\end{array}$ & $\begin{array}{l}\text { Test } \\
\text { error }\end{array}$ & $\begin{array}{c}\text { Training } \\
\text { algorithm }\end{array}$ & $\begin{array}{c}\text { Hidden } \\
\text { activation }\end{array}$ & $\begin{array}{l}\text { Output } \\
\text { activation }\end{array}$ \\
\hline 1 & MLP 4-6-2 & 0.886279 & 0.648977 & 0.011938 & 0.019339 & BFGS 68 & Tanh & Exponential \\
\hline 2 & RBF 4-13-2 & 0.721798 & 0.640185 & 0.024905 & 0.023927 & RBFT & Gaussian & Identity \\
\hline 3 & RBF 4-14-2 & 0.801942 & 0.650008 & 0.019026 & 0.019221 & RBFT & Gaussian & Identity \\
\hline 4 & MLP 4-5-2 & 0.727790 & 0.605069 & 0.024599 & 0.030921 & BFGS 62 & Tanh & Tanh \\
\hline 5 & RBF 4-16-2 & 0.736733 & 0.658528 & 0.023879 & 0.019539 & RBFT & Gaussian & Identity \\
\hline 6 & RBF $4-17-2$ & 0.815479 & 0.674258 & 0.018108 & 0.016974 & RBFT & Gaussian & Identity \\
\hline 7 & RBF 4-19-2 & 0.840660 & 0.709847 & 0.015854 & 0.016212 & RBFT & Gaussian & Identity \\
\hline 8 & MLP 4-9-2 & 0.860230 & 0.689380 & 0.014231 & 0.026251 & BFGS 47 & Tanh & Exponential \\
\hline 9 & RBF 4-14-2 & 0.710074 & 0.657801 & 0.026090 & 0.023534 & RBFT & Gaussian & Identity \\
\hline 10 & RBF 4-17-2 & 0.576614 & 0.669969 & 0.037016 & 0.020735 & RBFT & Gaussian & Identity \\
\hline 11 & RBF 4-26-2 & 0.405562 & 0.698839 & 0.066769 & 0.020288 & RBFT & Gaussian & Identity \\
\hline 12 & RBF 4-14-2 & 0.755550 & 0.643505 & 0.023142 & 0.021047 & RBFT & Gaussian & Identity \\
\hline 13 & MLP 4-4-2 & 0.847854 & 0.647499 & 0.015638 & 0.024218 & BFGS 75 & Tanh & Identity \\
\hline 14 & RBF $4-22-2$ & 0.806581 & 0.650498 & 0.018587 & 0.023813 & RBFT & Gaussian & Identity \\
\hline 15 & RBF 4-20-2 & 0.766031 & 0.607861 & 0.022248 & 0.027228 & RBFT & Gaussian & Identity \\
\hline 16 & RBF 4-27-2 & 0.876840 & 0.720086 & 0.012569 & 0.017491 & RBFT & Gaussian & Identity \\
\hline 17 & RBF 4-39-2 & 0.949091 & 0.733024 & 0.005481 & 0.015862 & RBFT & Gaussian & Identity \\
\hline 18 & MLP 6-6-13-2 & 1 & 0.99982 & 0.014231 & 0.026251 & $\mathrm{LM}$ & Tanh & Exponential \\
\hline
\end{tabular}

Table 4. Training, test, and validation regression results of ANN model

\begin{tabular}{|c|c|c|c|c|c|c|c|}
\hline & \multicolumn{3}{|c|}{ Training } & \multicolumn{3}{|c|}{ Test } & \multirow{2}{*}{$\frac{\text { Validation }}{\left(R^{2}\right)}$} \\
\hline & $\left(R^{2}\right)$ & $(R M S E)$ & $(M E P \%)$ & $\left(R^{2}\right)$ & $(R M S E)$ & $(M E P \%)$ & \\
\hline Surface roughness, SR & 1 & $3.94 \mathrm{E}-08$ & $1.31 \mathrm{E}-08$ & 0.99981 & $3.11 \mathrm{E}-08$ & $-8.3 \mathrm{E}-09$ & 0.99982 \\
\hline Surface hardness, SH & 1 & $2.81 \mathrm{E}-07$ & $1.5 \mathrm{E}-09$ & 0.99981 & $4.1 \mathrm{E}-07$ & $3.51 \mathrm{E}-10$ & 0.99982 \\
\hline
\end{tabular}

peated. To be able to get accurate results, three hidden layers were used. The number of neurons was iterated from 5 to 150 for each hidden layer. These loops were continued to obtain the best performance of the networks. The best performance of the network depends on the statistical errors (Table 3 ). Table 3 illustrates the behavior of the network with a varying number of neurons. Table 4 shows the training, test, and validation regression results for our improved ANN model. Tables 5a and 5b show inputs/outputs for a test of the ANN model and accuracy of the ANN model for test parameters.

\subsection{Interpreting the $A N N$ results}

The paper was interested in both experimental work and modeling with ANN methods. The experimental study results can be predicted for the ball burnishing processes using ANN techniques. As presented in Table 4 the statistical error levels for both training and testing data sets are evaluated. As the table illustrates, the network with three hidden layers of $4+6+6+13+2$ neurons at each layer provided the best results (Fig. 14).

Following the ANN model as illustrated in Fig. 6 set up using 4 neurons for the input layer and with $6+6+13$ processing elements at three hidden layers and finally, 2 neurons were used at the output layer. Representation of knowledge was accomplished by the weights in between the layers.

Regarding the statistical error analysis methods, using Levenberg-Marquardt (LM) learning algorithm technique for surface roughness and surface hardness the mean error value for the training data set are $\% 1.31 \mathrm{E}-08$ and $\%-1.5 \mathrm{E}-09$, respectively.

\section{Conclusions}

In this study, the impacts that occurred through the parameters used while conducting the burnishing process on the surface were examined. It was observed that the increase in the burnishing force reflects on the surface hardness positively in the burnishing process that was applied in the experimental samples. The surface hardness increased together with the increasing burnishing force. However, the increase in the burnishing force reflected on the surface roughness negatively.

The increase in the feed rate caused a decrease in 
Ta ble 5a. Improved ANN model inputs and output results (test)

\begin{tabular}{|c|c|c|c|c|c|c|c|}
\hline $\begin{array}{l}\text { Burnishing } \\
\text { force }(\mathrm{N})\end{array}$ & $\begin{array}{c}\text { Feed rate } \\
(\mathrm{mm} / \text { teeth })\end{array}$ & $\begin{array}{l}\text { Number of } \\
\text { revolutions } \\
\quad(\mathrm{rpm})\end{array}$ & $\begin{array}{c}\text { Ball } \\
\text { diameter } \\
(\mathrm{mm})\end{array}$ & $\begin{array}{l}\text { Average } \\
\text { surface } \\
\text { roughness }\end{array}$ & $\begin{array}{c}\text { ANN } \\
\text { surface } \\
\text { roughness }\end{array}$ & $\begin{array}{l}\text { Average } \\
\text { surface } \\
\text { hardness } \\
\text { (HB) }\end{array}$ & $\begin{array}{c}\text { ANN } \\
\text { Average } \\
\text { surface } \\
\text { hardness } \\
\text { (HB) }\end{array}$ \\
\hline 400 & 0.25 & 200 & 11.112 & 1.005 & 1.005 & 32.75 & 32.7500003 \\
\hline 300 & 0.25 & 200 & 13.494 & 1.1 & 1.1 & 41 & 41.0000000 \\
\hline 200 & 0.25 & 200 & 15.081 & 0.28 & 0.28 & 26.25 & 26.2500000 \\
\hline 100 & 0.25 & 200 & 16.669 & 0.155 & 0.155 & 23 & 23.0000000 \\
\hline 400 & 0.25 & 200 & 16.669 & 0.525 & 0.525 & 41 & 40.9999996 \\
\hline 200 & 0.25 & 300 & 13.494 & 0.58 & 0.58 & 26 & 25.9999990 \\
\hline 400 & 0.25 & 100 & 13.494 & 1.205 & 1.205 & 29.25 & 29.2500004 \\
\hline 100 & 0.15 & 200 & 11.112 & 0.645 & 0.645 & 22.75 & 22.7500007 \\
\hline 300 & 0.45 & 200 & 11.112 & 1.605 & 1.605 & 28.25 & 28.2500002 \\
\hline 200 & 0.15 & 300 & 11.112 & 0.55 & 0.55 & 21.75 & 21.7500005 \\
\hline 400 & 0.15 & 300 & 11.112 & 1.045 & 1.045 & 39 & 39.0000002 \\
\hline 400 & 0.45 & 300 & 11.112 & 1.945 & 1.945 & 29 & 28.9999988 \\
\hline
\end{tabular}

Table 5b. Regression results of improved ANN model (test)

\begin{tabular}{|c|c|c|c|c|c|c|c|c|c|}
\hline $\begin{array}{l}\text { Average } \\
\text { surface } \\
\text { roughness }\end{array}$ & $\begin{array}{c}\text { ANN } \\
\text { Average } \\
\text { surface } \\
\text { roughness }\end{array}$ & $R M S E$ & $R^{2}$ & $M E P$ & $\begin{array}{c}\text { Average } \\
\text { surface } \\
\text { hardness } \\
(\mathrm{HB})\end{array}$ & $\begin{array}{c}\text { ANN } \\
\text { Average } \\
\text { surface } \\
\text { hardness } \\
(\mathrm{HB})\end{array}$ & $R M S E$ & $R^{2}$ & $M E P$ \\
\hline 1.005 & 1.004999994 & $5.82 \mathrm{E}-09$ & 1 & $5.79 \mathrm{E}-09$ & 32.75 & 32.75 & $2.61 \mathrm{E}-07$ & 1 & $-8 \mathrm{E}-09$ \\
\hline 1.1 & 1.100000004 & $4.07 \mathrm{E}-09$ & 1 & $-3.7 \mathrm{E}-09$ & 41 & 41 & $6 \mathrm{E}-09$ & 1 & $-1.5 \mathrm{E}-10$ \\
\hline 0.28 & 0.279999997 & $3.21 \mathrm{E}-09$ & 1 & $1.15 \mathrm{E}-08$ & 26.25 & 26.25 & $2.03 \mathrm{E}-08$ & 1 & $7.74 \mathrm{E}-10$ \\
\hline 0.155 & 0.155000008 & $7.8 \mathrm{E}-09$ & 1 & $-5 \mathrm{E}-08$ & 23 & 23 & $4.39 \mathrm{E}-09$ & 1 & $-1.9 \mathrm{E}-10$ \\
\hline 0.525 & 0.524999969 & $3.07 \mathrm{E}-08$ & 1 & $5.85 \mathrm{E}-08$ & 41 & 41 & $4.14 \mathrm{E}-07$ & 1 & $1.01 \mathrm{E}-08$ \\
\hline 0.58 & 0.580000145 & $1.45 \mathrm{E}-07$ & 1 & $-2.5 \mathrm{E}-07$ & 26 & 26 & $9.74 \mathrm{E}-07$ & 1 & $3.74 \mathrm{E}-08$ \\
\hline 1.205 & 1.204999986 & $1.35 \mathrm{E}-08$ & 1 & $1.12 \mathrm{E}-08$ & 29.25 & 29.25 & $4.31 \mathrm{E}-07$ & 1 & $-1.5 \mathrm{E}-08$ \\
\hline 0.645 & 0.644999945 & $5.55 \mathrm{E}-08$ & 1 & $8.6 \mathrm{E}-08$ & 22.75 & 22.75 & $6.73 \mathrm{E}-07$ & 1 & $-3 \mathrm{E}-08$ \\
\hline 1.605 & 1.604999986 & $1.45 \mathrm{E}-08$ & 1 & $9.03 \mathrm{E}-09$ & 28.25 & 28.25 & $1.99 \mathrm{E}-07$ & 1 & $-7 \mathrm{E}-09$ \\
\hline 0.55 & 0.549999974 & $2.62 \mathrm{E}-08$ & 1 & $4.76 \mathrm{E}-08$ & 21.75 & 21.75 & $4.59 \mathrm{E}-07$ & 1 & $-2.1 \mathrm{E}-08$ \\
\hline 1.045 & 1.044999993 & $6.57 \mathrm{E}-09$ & 1 & $6.28 \mathrm{E}-09$ & 39 & 39 & $2.39 \mathrm{E}-07$ & 1 & $-6.1 \mathrm{E}-09$ \\
\hline 1.945 & 1.94500006 & $5.98 \mathrm{E}-08$ & 1 & $-3.1 \mathrm{E}-08$ & 29 & 29 & $1.24 \mathrm{E}-06$ & 1 & $4.28 \mathrm{E}-08$ \\
\hline
\end{tabular}

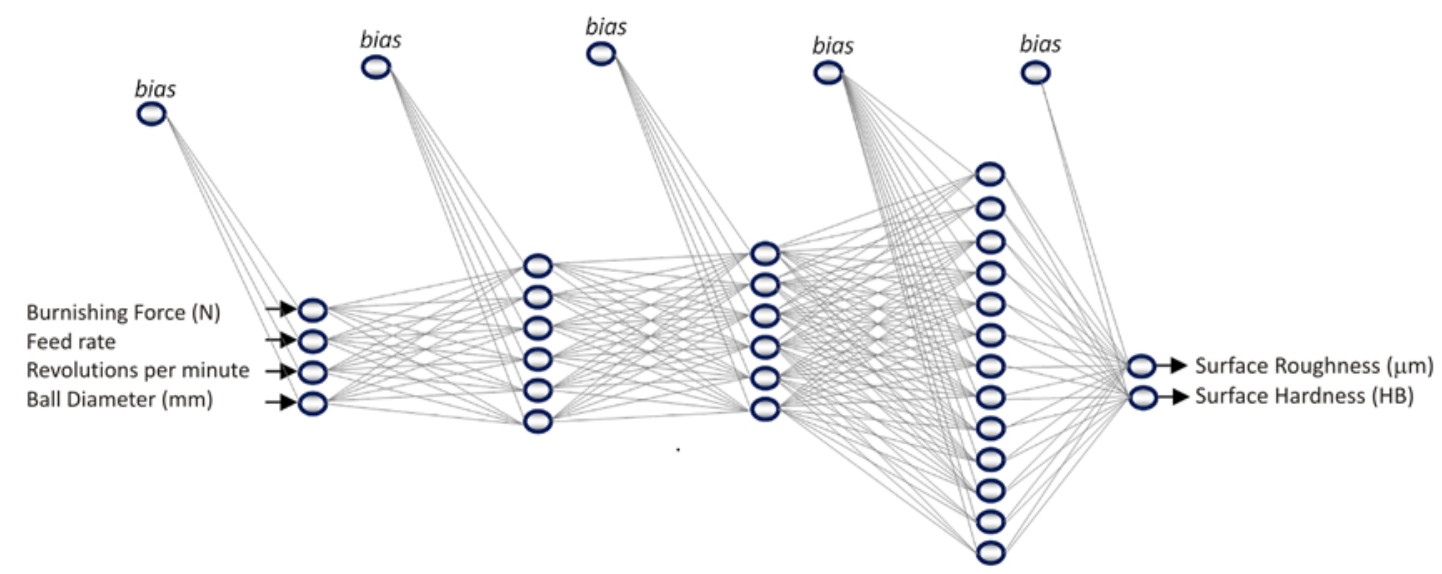

Fig. 14. ANN architecture with $4+6+6+13+2$ processing elements at three hidden layers. 
the surface hardness. According to the attained results of the experiment, it has been detected that the best feed rate is 0.25 for the surface hardness. The feed rate to be 0.25 and $0.35 \mathrm{~mm} \mathrm{rpm}{ }^{-1}$ in the test sample has ensured the provision of the best surface roughness values. All the feed rates after the amount of $0.35 \mathrm{~mm} \mathrm{rpm}^{-1}$ have caused distortions in the surface roughness.

When the parameter of the number of revolutions is taken into consideration, it is seen that the best surface roughness is attained with $100 \mathrm{rpm} \mathrm{min}^{-1}$ and $200 \mathrm{~N}$ burnishing force. The increase in the number of revolutions causes the distortion of the surface. In the conducted experiments, it is seen that the changes in the number of revolutions do not cause too great effects on the surface hardness. It has also been detected that as the number of revolutions increases, there is an increase in the surface hardness although it is little.

The increase in the ball diameter positively affects the surface roughness. In the experiments, the burnishing process that was conducted via a ball with a diameter of $16.669 \mathrm{~mm}$ (the greatest ball diameter having been used) gave the best surface roughness. The best surface hardness for the test sample was attained with a ball diameter of $15.081 \mathrm{~mm}$. While there were increases in the surface hardness up to the ball diameter of $15.081 \mathrm{~mm}$, decreases occurred after this diameter in the surface hardness.

As a result of the conducted tensile tests, it was revealed that the increase in the burnishing force used in the burnishing process positively affected the tensile strength of the material. The increase in the feed rate that was among the burnishing parameters negatively reflected on the tensile strength. The results of the best tensile strength were attained in the least feed rates. The increase in the number of revolutions and ball diameter among the burnishing parameters positively affected the tensile strength.

When the impacts of the parameters applied in the burnishing process on the microhardness of the test samples were examined, it was detected that the increase in the burnishing force positively affected the microhardness of the test sample surface. The best microhardness values were attained from the greatest burnishing forces $(400 \mathrm{~N})$. As was expected, the impact areas of the burnishing process as much as 2 $2.5 \mathrm{~mm}$ were detected for the test samples in the measurements conducted from the burnishing test sample surface towards the inside. The increase in the ball diameter and feed rate negatively affected the microhardness of the test sample part surface. If the microhardness and the impact on the inside of the test sample were requested to be high, it was revealed that the ball diameter should be kept small.

When the attained results are assessed overall, it could be said that the most significant parameters in the burnishing process are respectively the burnishing force and the feed rate. The other parameters used the number of revolutions and the ball diameter - are also efficient on the burnishing, but it was seen from the conducted experiments and with the attained results that their impacts were not as great as those of the burnishing force and feed rate. The best surface roughness value for the test sample $(0.155 \mu \mathrm{m})$ was attained with the $0.25 \mathrm{~mm} \mathrm{rpm}^{-1}$ feed rate, $100 \mathrm{~N}$ burnishing force, $200 \mathrm{rpm} \mathrm{min}^{-1}$ number of revolutions and $16.669 \mathrm{~mm}$ ball diameter. The best surface hardness value for the test sample (41 HB) was attained with the $0.25 \mathrm{~mm} \mathrm{rpm}^{-1}$ feed rate, $300 \mathrm{~N}$ burnishing force, $200 \mathrm{rpm} \mathrm{min}^{-1}$ number of revolutions and a $13.494 \mathrm{~mm}$ ball diameter.

\section{References}

[1] Basak, H., Goktas, H. H.: Materials and Design, 30, 2009, p. 1275. doi:10.1016/i.matdes.2008.06.063

[2] Gusel, L., Rudolf, R., Kosec, B.: Metalurgija, 48, 2009, p. 103.

[3] Karpe, B., Kosec, B., Kolenko, T., Bizjak, M.: Metalurgija, 50, 2011, p. 13.

[4] Vukelic, D., Miljanic, D., Randjelovic, S., Budak, I., Dzunic, D., Eric, M., Pantic, M.: Materials and Technology, 47, 2013, p. 43.

[5] El-Axir, M. H., Othman, O. M., Abodiena, A. M.: J. Mater. Process. Technol., 202, 2008, p. 435. doi:10.1016/i.jmatprotec.2007.10.040

[6] El-Axir, M. H.: Int. J. Mach. Tools Manuf., 40, 2000, p. 1603. doi:10.1016/S0890-6955(00)00019-5

[7] Hamadache, H., Laouar, L., Zeghib, N. E., Chaoui, K.: J. Mater. Process. Technol., 180, 2006, p. 130. doi:10.1016/j.jmatprotec.2006.05.013

[8] Basak, H., Ozkan, S., Taskesen, A.: Experimental Techniques, 35, 2011, p. 8. doi:10.1111/j.1747-1567.2009.00555.x

[9] Shiou, F. J., Hsu, C. C.: J. Mater. Process. Technol., 205, 2008, p. 249. doi:10.1016/j.jmatprotec.2007.11.244

[10] Luca, L., Neagu-Ventzel, S.; Marinescu, I.: Precis. Eng., 29, 2005, p. 253. doi:10.1016/i.precisioneng.2004.02.002

[11] Hassan, A. M., Momani, A. M. S.: Int. J. Mach. Tools Manuf., 40, 2000, p. 1775. doi:10.1016/S0890-6955(00)00018-3

[12] Hassan, A. M., Al Bsharat, A. S.: J. Mater. Process. Technol., 59, 1996, p. 250. doi:10.1016/0924-0136(95)02149-3

[13] Palka, K., Weronski, A., Zaleski, K.: Mater. Manuf. Eng., 16, 2006, p. 57.

[14] Gharbi, F., Sghaier, S., Hamdi, H., Benameur, T.: Int. J. Adv. Manuf. Technol., 60, 2012, p. 87. doi:10.1007/s00170-011-3598-6

[15] El-Axir, M. H., Othman, O. M., Abodiena, A. M.: J. Mater. Process. Technol., 196, 2008, p. 120. doi:10.1016/j.jmatprotec.2007.05.028

[16] El-Axir, M. H., El-Khabeery, M. M.: J. Mater. Process. Technol., 132, 2003, p. 82. doi:10.1016/S0924-0136(02)00269-8 
[17] El-Khabeery, M. M., El-Axir, M. H.: Int. J. Mach. Tools Manuf., 41, 2001, p. 1705. doi:10.1016/S0890-6955(01)00036-0

[18] Shirsat, U. M., Ahuja, B. B.: Indian Journal of Engineering and Material Sciences, 11, 2004, p. 391.

[19] Basak, H., Sonmez, F.: Journal of Polytechnic, 18, 2015, p. 125

[20] Sagbas, A.: Advances in Engineering Software, 42, 2011, p. 992. doi:10.1016/i.advengsoft.2011.05.021

[21] Li, F. L., Xia, W., Zhou, Z. Y., Jing, Z., Zheng, Q. T.: International Journal of Machine Tools \& Manufacture, 62,2012 , p. 67. doi:10.1016/j.ijmachtools.2012.06.001

[22] Esme, U.: Materiali in Tehnologije/Materials and Technology, 44, 2010, p. 129.

[23] Basak, H., Yucel, M.: In: Proceedings of Second International Iron and Steel Symposium (IISS'15). Eds.: Göloğlu, C., Yaşar, M. Karabuk, Iron and Steel Institute 2015 , p. 768 .

[24] El-Tayeb, N. S. M., Low, K. O., Brevern, P. V.: Journal of Materials Processing Technology, 186, 2007, p. 272. doi:10.1016/j.jmatprotec.2006.12.044

[25] Thamizhmanii, S., Saparudin, B., Hasan, S.: Journal of Achievements in Materials and Manufacturing Engineering, 22, 2007, p. 95.

[26] Rao, J. N. M., Reddy, A. C. K., Rao, P. V. R.: Indian Journal of Science and Technology, 3, 2010, p. 737. doi:10.17485/ijst/2010/v3i7/29805

[27] Shiou, F. J., Chen, C. H.: Journal of Materials Processing Technology, 140, 2003, p. 248. doi:10.1016/S0924-0136(03)00750-7

[28] de Lacalle, L. N. L., Lamikiz, A., Muñoa, J., Sánchez, J. A.: International Journal of Machine Tools \& Manufacture, 45, 2005, p. 1659. doi:10.1016/j.ijmachtools.2005.03.007

[29] Luca, L., Neagu-Ventzel, S., Marinescu, I.: Precision Engineering, 29, 2005, p. 253. doi:10.1016/j.precisioneng.2004.02.002

[30] Ibrahim, A. A., Rabbo, S. M. A., El-Axir, M. H., Ebied, A. A: Journal of Materials Processing Technology, 209, 2009, p. 2428. doi:10.1016/j.jmatprotec.2008.05.040
[31] Li, F. L., Xia, W., Zhou, Z. Y., Jing, Z., Zheng, Q. T.: International Journal of Machine Tools \& Manufacture, 62,2012 , p. 67. doi:10.1016/j.ijmachtools.2012.06.001

[32] Grzesik, W., Zak, K.: Journal of Materials Processing Technology, 212, 2012, p. 315. doi:10.1016/j.jmatprotec.2011.09.017

[33] Dabeer, P. S., Purohit, G. K.: Advances in Production Engineering and Management, 5, 2010, p. 111.

[34] Jawalar, C. S., Walia, R. S.: Journal of Mechanical Engineering Research, 1, 2009, p. 038.

[35] Tian, Y., Shin, Y. C.: International Journal of Machine Tools \& Manufacture, 47, 2007, p. 14. doi:10.1016/j.ijmachtools.2006.03.002

[36] Yeldose, B. C., Ramamoorthy, B.: Journal of Materials Processing Technology, 207, 2008, p. 350. doi:10.1016/j.jmatprotec.2008.06.058

[37] Dyl, T.: Journal of KONES Powertrain and Transport, 18, 2011, p. 123.

[38] Rao, M. J. N., Reddy, C. K. A., Rao, R. P. V.: International Journal of Applied Engineering Research, 1, 2011, p. 77.

[39] Low, K. O., Wong, K. J.: Tribology International, 44, 2011, p. 144. doi:10.1016/j.triboint.2010.10.005

[40] Basak, H., Gural, A.: In: Proceedings of 8th Engineering And Technology Symposium. Ankara, Çankaya University 2015, p. 57.

[41] An American National Standard, Annual Book of ASTM Standards, Vol 02.02., 03.01.

[42] Ozkan, M. T.: Energy Education Science and Technology. Part A: Energy Science and Research, 30, 2012, p. 621 ,

[43] Ozkan, M. T.: Indian Journal of Engineering \& Materials Science, 20, 2013, p. 259.

[44] Ozkan, M. T., Eldem, C., Sahin, I.: Materiali in Tehnologie/Materials and Technology, 48, 2014, p. 81.

[45] Ozkan, M. T.: Materials Testing, 57, 2015, p. 889. doi:10.3139/120.110793

[46] Ozkan, M. T., Ulas, H. B., Bilgin, M.: Materiali in Tehnologije/Materials and Technology, 48, 2014, p. 227. 